\title{
A CRITICAL REAPPRAISAL OF NUCLEAR POWER PLANT SAFETY AGAINST ACCIDENTAL AIRCRAFT IMPACT
}

\author{
J. D. RIERA \\ Curso de Pós-Graduacão em Engenharia Civil, Universidade Federal do Rio Grande do Sul, \\ Av. Osvaldo Aranha, 99, Porto Alegre, RS, Brazil
}

Abstract

The overall problem of Nuclear Power Plant safety against an accidental aircraft impact is discussed in relation with its structural analysis and design. Associated risks, such as fire, which is a potential source of damage for buildings and other structures, are not considered.

The paper is divided in two parts. In Part I different approaches used for determining the reaction-time curve are discussed. The influence on the results of target motions is examined next. It is shown that for the evaluation of structural response an aircraft-structure interaction analys is is usually an unnecessary refinement, "mean" reaction-time and impact area-time curves being sufficient to define the excitation. Preliminary results for oblique impact are also given. Since the conditional probability of a normal impact is very small, the consideration of oblique impact may become acceptable in future design criteria.

In Part II, available solutions for the resulting structural dynamic problem are reviewed. The feasibility of resorting to a static analysis is also discussed. Present practices to evaluate floor response spectra are reviewed next. The short-comings of the "deterministic" approach are pointed out. It is proposed to define the excitation as a mean plus a fluctuating force. The latter is treated as a nonstationary random process and the problem solved by numerical integration in the time domain. Although such solutions get prohibitively expensive when the number of degrees of freedom becomes large, results obtained for simple models may help to clarify which are the important variables of the problem.

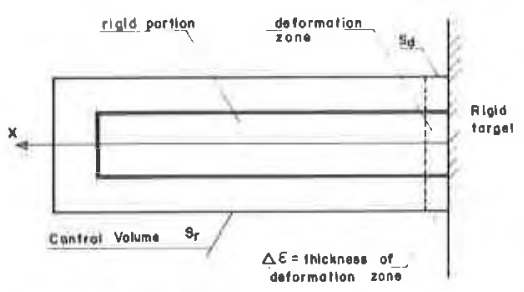

Fig. 2.1. Model of impinging soft missile.

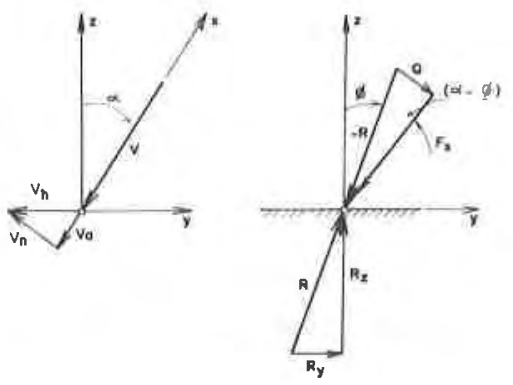

Fig. 4.1. Notation and sign convention for oblique impact velocities and forces. 


\section{Introduction}

The U.S. National Regulatory Commission (ex-AEC) requested in 1968 the safety evaluation of the 3-Mile Island Nuclear Power Station against an accidental aircraft strike. Consequently, the effect of an aircraft crash against the steel-lined prestressed concrete containment structure had to be determined. The main conclusion of the ensuing analysis was that the containment building could withstand, with only minor damage, the normal impact of a Boeing 720 or similar commercial aircraft impinging at $103 \mathrm{~m} / \mathrm{sec}$. The potential effects of fire were also assessed and adequate protective measures taken, al though no verification of impact-induced vibrations of equipment was performed at the time' .

For purposes of structural analysis, which is the subject of this paper, the orerall impact problem was uncoupled ${ }^{2}$. The time dependent reaction $F_{x}(t)$ of a flat rigid barrier against a normally impacting aircraft was evaluated first, for which purpose the services of a consulting firm specialized in aviation problems had to be retained ${ }^{3}$. The response to $F_{x}(t)$ of critical structures was calculated independently.

Riera ${ }^{2}$ considered that the approach was justified because (a) the reaction time curve $F_{X}(t)$ should not be significantly altered by small displacements of the target and (b) uncoupling considerably simplifies the mathematical models required, thus greatly reducing costs. The basic assumptions and other aspects of the overall problem were discussed by Lorenz ${ }^{4}$, also in relation to the 3 Mile Island Station, which remains as one of the only two plants to be designed against accidental aircraft impact in the USA, the other one being the Seabrook Nuclear Station ${ }^{6}$. In fact, the NRC only requires such design when the aircraft crash results in a probability of radioactive release in excess of 100 CFR 100 guidelines larger than $10^{-7}$ year. Consequently, in the USA only plants in the vicinity of large airports must be specifically design to resist aircraft impact ${ }^{13}$.

In other countries, however, the aircraft crash is normally explicitly considered in design. One such case is West Germany, which adopted as the limiting design condition the impact of a military fighter aircraft at flight speed. Most other nations follow the USA criteria, i.e. normal impact of a commercial aircraft - usually of the Boeing 720 or 707 class at 7 anding speed-and designing against such hazard only when the site is in the proximity of an airport or under a heavy air route 13,14 .

Thus, after 1974 several plants in Switzerland ${ }^{12}$ and Belgium ${ }^{33}$, and most Nuclear Power Stations in $W$. Germany ${ }^{14}$ had to be specifically designed to resist an accidental aircraft strike. This spurred a widening interest on the subject, which resulted in the publication of a large number of relevant contributions in the technical literature. The objective of this paper is to present a critical reappraisal of those developements, in particular those concerned with procedures for determining the reaction-time curve and the resulting structural response, including floor spectra for equipment design.

One topic of crucial importance for eventual revisions of present design criteria is related to the determination of probability of occurrence of the hazard under consideration. These topics, which are dealt with by Chelapati 'et al', Wal $1^{9}$, Biringer ${ }^{18}$, Nigoyi 'et a $7^{135}$, Ravindra ${ }^{36}$ and Bauer \& Schueller ${ }^{43}$, among others, are out of the scope of this paper. A brief discussion is included, however, about the conditional probability of a 'normal' impact which, in conjunction with preliminary results on the effect of oblique impact 
presented herein, may contribute to the developement of improved design criteria.

\section{Evaluation of reaction curve for aircraft impact against a rigid target}

For any mass system, the relation between force and momentum is the same as for a single particle:

$$
F_{x}=\frac{d M_{x}}{d t}
$$

in which $F_{x}$ is the resultant $x$ force and $M_{x}$ the $x$-momentum. Now, let $m$ be the mass lying within a fixed control volume $S$ at an arbitrary reference time $t_{a}$. After a time interval $d t=t_{b}-t_{a}$, the boundary of the system will, in general, no longer coincide with $S$. Further more, let $M_{x a}$ and $M_{x b}$ denote the $x$-momenta of al1 matter inside $S$ at $t_{a}$ and $t_{b}$, respectively, while $d M_{x i n}$ and $d M_{x o u t}$ represent the in - and outflows of $x$-momentum through the surface of $S$ during $\mathrm{dt}$. The resulting force acting on the control volume $S$ may be expressed as follows:

$$
F_{x}=\frac{M_{x a}-M_{x b}}{d t}+\frac{d M_{x o u t}-d M_{x i n}}{d t}
$$

The simplified model of a soft missile introduced in Refs. (2) and (3), assumes the existence of two zones, a negligibly thin "deformation" zone adjacent to the target surface - within control volume $S_{d}$ in Fig. 2.1 - and a rigid zone - within control volume $S_{r}$ in the same figure. Moreover, let $S=S_{d} \cup S_{r}$. If $t_{a}$ indicates now "contact time" and eq. (2.2) is applied to $S$, then:

$$
\begin{aligned}
& M_{x a}=m V \\
& M_{x b}=(m-d m)(V-d V)+d M_{x, d m}
\end{aligned}
$$

in which $V$ is the velocity of mass $m$ at time $t_{a}$, dm the mass element that enters into the deformation zone $S_{d}$ during $d t$ and $d M_{x, d m}$ the 'residual' $x$-momentum of mass dm. Introducing the notation $d M_{x, d m}=V_{r} d m$ and noting that in this case the second term in the right hand side of eq. $(2.2)$ is null, it results:

$$
F_{x}=m \frac{d V}{d t}+\left(V-V_{r}\right) \frac{d m}{d t}
$$

One basic assumption of Riera ${ }^{2}$ and Haley and Turnbow ${ }^{3}$ is that the 'residual' velocity $V_{r}$ is zero. Then, a straight application of Newton's law to the rigid portion of the missile permits equating the term $m \frac{d V}{d t}$ to the load $P_{C}$ necessary to crush or buckle the missile. Moreover, writing

$$
\frac{d m}{d t}=\mu V
$$

$\mu$ being the mass density of the missile per unit length, eq. (2.5) becomes ${ }^{2}{ }^{3}$ :

$$
F_{x}(t)=P_{c}[x(t)]+\mu[x(t)] V^{2}(t)
$$

in eq. (2.7), $x(t)$ denotes the distance from the nose of the missile:

$$
x(t)=\int_{0}^{t} V(\xi) d \zeta
$$


Eq. (2.7), derived from the momentum equation, permits the determination of the reaction time curve for any soft missile, such as a commercial aircraft at landing speed impinging against a rigid target.

In a attempt to improve the preceding formulation, Hornyik ${ }^{24}$ considered energy balance as well, which, assuming a rigid-perfectly plastic behavior of the missile material, leads to the equation:

$$
P_{c}=\frac{1}{2}(1-f) \mu v^{2}+m \frac{d V}{d t}
$$

Expressing the themal and kinetic energies - in the directions nomal and parallel to the target surface - of the system of particles $\mathrm{dm}$ as $0.5 \mathrm{dm} \mathrm{V}_{\mathrm{T}}{ }^{2}, 0.5 \mathrm{dm} \mathrm{V}_{\mathrm{x}}{ }^{2}$ and $0.5 \mathrm{dm} \mathrm{V}_{\mathrm{p}}{ }^{2}$, thene

$$
f=\frac{v_{T}^{2}+v_{x}^{2}+v_{p}^{2}}{v^{2}}
$$

In Ref. (24) both the thermal energy and the kinetic energy in the $x$-direction are assumed zero, the last hypothes is in accordance with the value $V_{R}=0$ adopted in eq. (2.5) Note that since the acceleration $\frac{d V}{d t}$ must always be negative, meaning that the rigid portion is at all times being slowed down, coefficient $f$ must satisfy the condition $f \geq 1-2 \mathrm{P}_{c} / \mu v^{2}$. Introduc tion of eq. (2.9) into (2.5) leads to the expression:

$$
F_{x}=P_{C}+\frac{1}{2}\left(1+f-\frac{2 V_{r}}{v}\right) \mu v^{2}
$$

The coefficients $f$ and $v_{r}$ depend on the velocity distribution and thermal energy gain of mass dm within the deformation zone. It seems clear, moreover, that using the simple model proposed in Refs. (2) and (3) and the momentum and energy balance equations alone, the value of coeffi cient $0.5\left(1+f-2 V_{r} / V\right)$ cannot be found, additional assumptions being needed to obtain a unique solution. Lacking sufficient experimental evidence, it appears that the conservative values $f=1$ and $v_{r}=0$ that led to eq. (2.7) should be maintained. This point will be discussed further in connection with Rice and Bahar's proposal ${ }^{10}$.

Refinements, such as those proposed by Lange and Laue ${ }^{8}$, to improve eq. (2.7) by describing more accurately the material behavior up the crushing point of the missile, are questionable on the grounds that there is a general lack of information concerning both the material behavior at very high strain rates and the structural lay-out, mechanical properties, etc. of the impacting aircraft. Similar arguments are sustained by $\mathrm{Kar}^{41}$, who advocates an even simpler form of eq. (2.7). Assuming that $\mu(x)$ and $P_{C}(x)$ vary linearly between 0 at $x=0$ and $x=L$ and maximum values at $x=L / 2$, Kar obtains ${ }^{41}$ :

$$
\left(F_{x}\right)_{\text {max }} \cong 2 P_{c}+1.5 \frac{\mathrm{W}}{\mathrm{gL}} \mathrm{V}_{0}^{2}
$$

in which $W$ denotes the total weight of the aircraft, $L$ its length and $V_{0}$ its velocity just before impact. $F_{X}(t)$ according to this formulation would consist of a triangular pulse of duration $t_{d}=V_{0} / L$. Observe that Kar is implicity assuming that $0.5\left(1+f-2 V_{r} / V\right)=0.75$. Rice and Bahar ${ }^{10}$, on the other hand, sustain that the above factor should be $1 / 2$. Moreover, in a more recent contribution ${ }^{47}$, they presented an altemative derivation of the 
equation for calculating the reaction-time history. The pirfall of Rice and Bahar approach appears to be admiting a continuous $x$-velocity distribution throughout the control volume $S$, in conjunction with the assumption that the thickness of $S_{d}$ is mathematically zero, which results in a finite jump of $V$ at the missile-target interface, anyway. In fact, the thickness of $S_{d}$ may be expected to be negligible in comparison with the length of the missile, but needs not be mathematically null. Moreover, both the residual velovity $v_{p}$, as well as the effective 'velocities' $V_{x}, V_{T}$ and $V_{p}$ introduced above, must be interpreted as statistical means since dm consists, in general, of a larger number of particles moving with different speeds in different directions. With all their mathematical subtilties, it seems to the author that what Rice and Bahar really found is a lower limit to the reaction-time curve for the model of Refs. (2 - 4)

The preceding considerations apply to soft missiles. An approach that involves more computing effort was proposed by Drittler and Gruner ${ }^{15}$. The procedure was applied in Ref.(16) by the same authors to determine the reaction-time curve for a fast flying military aircraft, which was adopeted as design criteria in W. Germany. Bi-linear elasto-plastic material behavior and geometric linearity were assumed. The method may be used as well in case of "hard" missiles, such as an aircraft engine. It may aiso be useful to again some insight about the frequency content of the reaction-time history, subject that will be discussed 1 ater. Nevertheless, the influence of the model discretization on the results of Ref. (16) deserves additional research.

In the most comprehensive study of the problem published to date, Wolf 'et al'28 show that the reaction-time curve for large commercial aircraft computed by means of eq. (2.7) are practically indistinguishable from that obtained by modelling the aircraft with lumped masses interconnected by elasto-plastic springs. Fig. 4.5 shows that even for the case of military aircraft, the solution using eq. (2.7) yields a fairly good description of the mean value of the reaction-time curve. Since Larsson and Lundsager ${ }^{27}$ also computed the $F_{x}(t)$ history for a Phantom F4 at an impacting speed of $215 \mathrm{~m} / \mathrm{sec}$ - curves 16 and $17 \mathrm{in} \mathrm{Ref.} \mathrm{(27)} \mathrm{-}$ which differ significantly from that obtained by wol $f^{28}$, the author independently checked those results - curve (a) in Fig. 4.5. The differences between the curves shown in the literature is atributed to variation in the parameters adopted for the crushing strength.

\section{Influence of target flexibility on reaction-time curves}

One of the basic assumptions of Refs. $(2-4)$ is that a non-collapsing structure may be idealized, for determining a mean reaction-time diagram, as a rigid target. Of course, in case of non-rigid targets the reaction calculated by means of eq. (2.7) should furnish an upper bound to the "exact" value. The influence of deformations of the target on $F_{x}(t)$ has been investigated using different approaches. Drittler 'et a 1'25, using the same mode 1 of Refs. ( 2 - 3), obtained the following equation for the case of a target that moves in the $x$-direction with velocity $v_{a}(t)$ :

$$
F_{x}(t)=P_{c}\left(x-x_{a}\right)+\mu\left(x-x_{a}\right)\left(V-V_{a}\right)^{2}-\frac{d V_{a}}{d t} M_{a}
$$

in which $M_{a}$ denotes the crushed mass at the aircraft-target interface, and $x_{a}=f_{0}^{t} v_{a}(\xi) d \zeta$ 
Several case studies by Drittler 'et al ${ }^{25}$ indicated that the impact force is not significantly affected by yielding of the target. Clearly, the effect is more pronounced for military fighter planes than for large commercial aircraft, in which case deformations of the target - of order of magnitude as may be expected in non collapsing nuclear structures - do not affect the results whatsoever. Wolf 'et al ${ }^{28}$ conducted an extensive parametric study, both on the basis of eq. (3.1) as well as using a lumped-mass model of the impinging aircraft They show conclusively that in case of commercial aircraft, motion of target does not affect the resuits, from a practical point of view. Also using a lumped-mass model, Nabold and Schildknecht ${ }^{34}$ reached the same conclusion.

\section{Reaction-time curves for oblique impact}

Normal incidence has been assumed in all studies of the impact problem known to the author. On the other hand, reaction-time curves for oblique impact are of interest for two reasons: (a) al though normal impact is likely to be the most unfavourable condition for the verification of the target structure, it is by no means obvious that the same statement is applicable to floor response spectra and (b) given a point of impact, the conditional probability of normal aircraft incidence is very small, fact that may be taken into consideration in establishing new design criteria* In this section, reaction-time curves for a Boeing 707-320 and a Phantom F4 impacting obliquely on a rigid target are given. They were determined using the simplified approach described below.

Let $\alpha$ indicate the angle of incidence, as shown in Fig. 4.1 (a). It is assumed that eq. (3.1) is applicable, and that the crushed mass $M_{a}$ separates upon impact from the rigid portion and may be taken equal to zero.

It is further assumed that a "friction angle" between the impacting end and the target surface may be reliably estimated. Thus, if a $<\phi$, the point of impact would not move along the target surface and the vertical and horizontal reactions $R_{z}$ and $R_{y}$ would be given by:

$$
R_{z}=F_{x}(t) \cos \alpha ; \quad R_{y}=F_{x}(t) \sin \alpha ; \alpha<\phi
$$

If $\alpha>\phi$, on the other hand, the total reaction $R$ makes an angle $\phi$ with the vertical and an unbalanced component normal to $F_{x}$ appears. This force, denoted by $Q$ in Fig. 4.1 (b), causes the rigid portion to displace in the direction nomal to $0 x$ and to rotate around its mass center. If $y_{0}$ and $z_{0}$ indicate the coordinates, with respect to the $y-z$ reference system, of the mass center 0 of the uncrushed portion, then the following equations may be written, in which $I_{m}$ represents the mass moment of inertia of the rigid portion with respect to 0 and $L_{0}$ is distance between 0 and the instantaneous point of impact.

* If it is assumed that the conditional probability $P(\beta)$ of having an accidental impact on a flat surface with an angle of incidence less than $\beta$ is equal to the area of the spherical cap defined by $\beta$ referred to the area of a hemisphere of the same radius, then $P(\beta)=1-\cos \beta$. Defining as "normal" impact those cases for which $\alpha<15^{\circ}$, it follows that its conditional probability is about $3.4 \%$. 


$$
\begin{aligned}
& m \frac{d^{2} y_{0}}{d t^{2}}=-Q(t) \cos \alpha+P_{c}(t) \sin \alpha \\
& m \frac{d^{2} z_{0}}{d t^{2}}=Q(t) \sin \alpha+P_{c}(t) \cos \alpha \\
& I_{m} \frac{d^{2} \alpha}{d t^{2}}=Q L_{0}
\end{aligned}
$$

Eqs. (4.3 - 5) were numerically integrated using a central finite - difference scheme in conjunction with iteration after each time step. Note that $\left(V-V_{a}\right)$ in eq. (3.1) is given by:

$$
V-V_{a}=\frac{d z_{0}}{d t} \frac{\cos 2 \alpha}{\cos \alpha}-\frac{d \alpha}{d t} L_{0} \tan \alpha
$$

Figs. (4.2) to (4.4) show the vertical and horizontal reactions as well as the coordinate $y$ of the impact point for a Boeing 707-320, for normal and two angles of oblique incidence. Similarly, Figs. $(4.5-6)$ give the results obtained for a Phantom $F 4$ for $\alpha(0)=0^{\circ}$ and $\alpha(0)=30^{\circ}$. In all cases it was assumed that $\phi=25^{\circ}$. These results permit drawing the following tentative conclusions:

a) For high impact velocities and angles of incidence $\alpha(0)$ not too close to $90^{\circ}, \alpha$ does not change significantly during impact.

b) In those situations the maximum value of the reaction-time curve is approximately proportional to $\cos \alpha(0) \cdot \cos [\alpha(0)-\phi]$.

The possibility of a bending failure of the fuselage, due to the moment produced by $Q$, has not yet been introduced into the formulation, This effect is probably important for angles of incidence much larger than the angle of friction and is presently under study.

Note

On account of its length, Part II has not been included herein. The complete paper will be available for distribution to interested persons during the conference.

\section{List of References}

1. GILBERT ASSOC. INC., 3-Mile Island Preliminary Safety Analysis Report, Docket No 50-289, Supplement 5, March 1968, Report prepared for Metropolitan Edison Co.

2. J.D.RIERA, "On the Stress Analys is of Structures Subjected to Aircraft Impact Forces", Nuclear Engineering and Design 8, (1968), pp. 415-426.

3. J.L.HALEY and J.W.TURNBOW: "AVSER Final Report 68-3", Report prepared by Dynamic Science, Phoenix, Arizona, for Gilbert Assoc., Inc., April 1968.

4. H.LORENZ: "Aircraft Impact Design", Power Engineering, Nov. 1970, pp.44-46.

5. H.T.Y.YANG and D.A.GODFREY: "Structural Analys is of Aircraft impact on a Nuclear Containment Vessel and Associated Structures", J.Nuclear Engin. \& Design, Vol.II, 1970.

6. UNITED ENGINEERS AND CONTRACTORS: Seabrook Station Aircraft Impact Analysis, Dockets No 50-443/444, and Supp1., Jan \& May 1975. 
7. C.V.CHELAPATI, I.B.WALL, R.P.KENNEDY: "Probabilistic Assesment of Aircraft Hazard for Nuclear Power Plants", Ist. SMIRT Conference, Berlin, St 1971, Bol. 5, Paper J4/1. (publ. in Nuclear Engin. \& Design, 19, 1972, pp. 333-364).

8. L.LANGE, H.LAUE: "Dynamishe Assesment of Aircraft Risk for Nuclear Power. Plants", Nuclear Safety, 15, № 3, May-June 1974.

9. I.B.WALL: "Probabilistic Assesment -of Aircraft Risk for Nuclear Power Plants", Nuclear Safety, 15, No 3, May-June 1974.

10. J.S.RICE and L.Y.BAHAR: "Reaction-time relationshipe and Structural Design of Reinforced Concrete Slabs and Shells for Aircraft Impact", 3rd. International SMIRT Conference, London, Set 1975, Vol. 4, Part J, Paper J5/3.

11. R.SHARPE, H.KAMIL \& R.SCANLAN: "Analysis of an Aircraft Impact on a Reactor Building", Ibid, Paper J5/4.

12. P.DEGEN, H.FURRER and J.JEMIELEWSKI: "Structura? Analysis and Design of a Nuclear Power Plant Building for Aircraft crash effects", ELCALAP Seminar, in connection with 3rd SMIRT Conf. Berlin, Set. 1975.

13. J.D.STEVENSON: "Survey of Extreme Load Design - Regulatory Agency Licensing Requirements for Nuclear Power Plants". Nuclear Engin. \& Design, Vol. 37, No 1, April 1976.

14. J.A.RICHARDSON: "Summary Comparison of West European and U.S. Licensing Regulations for LWR'S", Nuclear Engineering Internationa], Feb. 1976.

15. K.DRITTLER and P.GRUNER: "Calculation of the total force acting upon a rigid wall by projectiles", Nuclear Engin. \& Design, Vol. 37, 1976, pp. 231-244.

16. J,DRITTLER and P.GRUNER: "The force resulting from impact of a fast flying military aircraft upon a ridig wal1", ibid pp. 245-248.

17. B.REBORA, TH ZIMMERMANN and J.P.WOLF: "Dynamic Rupture Analys is of Reinforced Concrete Shel1s", Nuclear Engin. \& Design, 37, (1976), NQ 2.

18. B.E.BIRINGER: "Assesments of the Probability of Aircraft Impact with the Sandia Pulsed Reactor Building 836", Sandia Laboratories, SAND75, 0366 , Nov 76.

19. W.ZERNA, G.SCHNELLENBACH and F.STANGENBERG: "Optimized Reinforcement of Nuclear Power Plant Structures for Aircraft impact forces", Nuclear Engin. \& Design 37 (1976) pp.313-320

20. M.SCHAKL and H.WOLFEL: "Response of equipment in Nuclear Power Plants to Aircraft Crash", Nuclear Engin. \& Design, 38, (1976), pp.567-582.

21. R.DANISH, U.GRAUBNER: "Inelastic Behavior of reinforced concrete structures subjected to induced vibrations of aircraft impact or gas closed explosion", 4Th International SMIRT Conf., San Francisco, 1977, Vo1. J, Paper J9/2.

22. G.SCHNELLENBACH and F.STANGENBERGER: "Design of Concrete Containment for Aircraft Impact", ibid, Paper J8/4.

23. F.STANGENBERG and W.ZERNA: "Extreme load resistant design of Nuclear Power Plant Structures", ibid, Paper J8/5.

24. K.HORNYIK: "Analytic Modelling of the impact of soft missiles on protective walls", ibid, Vol. J, Paper J1/3.

25. K. DRITTLER, P.GRUNER and J.KRIVY: "Calculation of forces arising from impacting projectiles upon yielding structures", ibid, Vol. J., Paper JT/4.

26. R.SCHMIDT, H.HECKHANSEN, C.CHEN, P.J.RIECK and G.W.LEMONS: "Structural Design for Aircraft 8 
Impact Loading", ibid, Vol. J, Paper J8/2.

27. G.LARSSON and P.LUNDSAGER: "On the response of a Reactor Building and its equipment to Aircraft crash", ibid, Vol. J, Paper J9/4.

28. J.P.WOLF, K.M.BUCHER and P.E.SKRIKERUD: "Response of equipment to Aircraft Impact", ibid, Invited Paper J9/5 (publ. in Nuclear Engin. \& Design, 47, 1978, pp.169-193).

29. A.KAISER, N. KRUTZIK, G.WINKEL and K.H.SCHRADER: "Local and Global Response of Reactor Buildings at the Loadcase Aircraft Impact", ibid, Vol. J, Paper J8/3.

30. D. CARLTON, A.BEDI: "Theoretical Study of Aircraft impact of Reactor Containment Structures", ibid, Vol. J, Paper J8/7.

31. V.B.KOTULLA and V.HANSSON: "Berechnung zum Flugzeugabsturz auf unterirdische Betonkanale mit schutzplatte am Reaktorgebaude", ibid, Vol. J, Paper J8/8.

32. H.WOLFEL: "Comments on the effects of the three external load cases - earthquake, Airplane crash, outer explosion - on the design of buildings and equipment of nuclear facilities a comparison", ibid, Vol. J, Paper J9/3.

33. J.P.FUZIER, M.H.CHEYREZY and C.P.DUFOUR: "Specific Problems Concerning Aireraft Impact on Nuclear Containment Vesse10", (in French) ibid, Vol. J, Paper J8/6.

34. C.NABOLD and P.O.SCHILDKNECHT: "Material" Nonlinear Analys is of Nuclear Power Plant Structures subjected to an Aircraft Impact", Applications using ADINA, Proceedings of the ADINA Conference, Ang 1977, id. by Klaus - Jurgen BATHE, MIT, Mass, 1977.

35. P.K.NIGOYI, R.C.BORITZ and A.K.BHATTACHARYYA: "Safety Design of Nuclear Power Plants Against Aircraft Impacts", American Nuclear Society Thermal Reactor Safety Meeting, Sun Valley, Idaho, July-Aug 1977.

36. M.K.RAVINDRA: "Load Combinations for Natural and man-made Hazards in Nuclear Structural Design", ibid.

37. J.D.RIERA: "Aplicaçāo do método das variāveis de estado ao estudo de sistemas dināmicos sob excitaçōes aleatōrias não estacionārias", Anais do IV Congresso Brasileiro de Engenharia Me cānica, P.aper No A-22, Florianōpolis, 1977, pp.255-268.

38. A.K.KAR: "Projectile Penetration into buried structures", J, of the Structural Division, ASCE, Vol 104, ST1, Jan 1978.

39. K.H.SCHRADER, A.KAISER and N.KRUTZIK: "Comparison of the Dynamic Response of the Structure of a Typical PWR-Reactor Butlding to the load cases earthquake, atrcraft impact and explosion, "Proceedings, Conf.on Structural Analysis, Design \& Construction in Nuclear Power Plants", UFRGS, Porto Alegre, Brazi1, Abril 1978. Vol. 1, pp.41-53.

40. G.EICKE: "Extreme load design of PW Type Reactor Buildings and the treatment of related problems", ibid, Vol. 1, pp.189-202.

41. A.K.KAR: "Design for aircraft Impact", ibid, Vol I, pp. 423-436.

42. C.CHEN, P.J.RIECK: "Soft Shel1 hard core concept for aircraft impact design", ibid, Vol I, Pp.465-470.

43. J.BAUER and G.I.SCHUELLER: "Probabillstic Aspects of Containment Design Against Extemal Hazards", ibid, Vol III, pp.839-854.

44. P.G.BIGNON: "Anālise dināmica para reatores nucleares submetidos a forças de impacto", ibid, Vol. III, pp. 1125-1140.

45. R.DANISCH, U.GRAUBNER: "Inelastic Analysis and Design of Reinforced Concrete Structures 
Submitted to induced Vibrations of Extreme Events, ibid, Vol II, pp. 633-644.

46. H.KAMIL, N.KRUTZIK, G.KOST \& R.SHARPE: "An Overview of major aspects of the aircraft impact problem", Nuclear Engineering \& Design 46, (1978), pp.109-121.

47. L.Y.BAHAR and J.RICE: "Simplified derivation of the reaction-time history in aircraft impact on a Nuclear Power Plant", Nuclear Engineering \& Design, 49, (1978), pp.263-268.

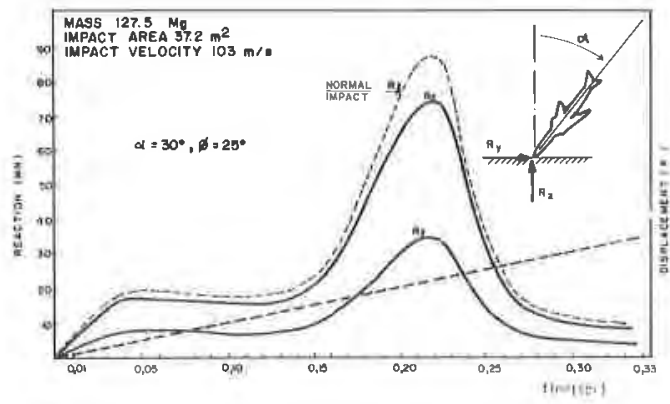

Fig. 4.2. Vertical and horizontal reaction and displacement of contact point for a Boeing 707-320 impinging against rigid target $\left(\alpha=0^{\circ}\right.$ and $\left.30^{\circ}\right)$.

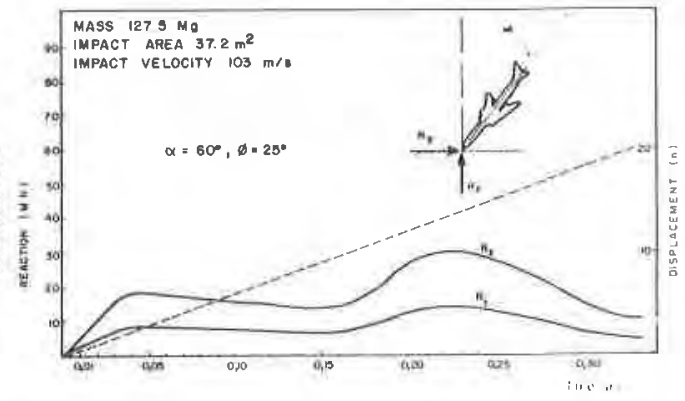

Fig. 4.3. Vertical and horizontal reaction and displacement of contact point for a Boeing 707-320 impinging against rigid target $\left(\alpha=60^{\circ}\right)$.

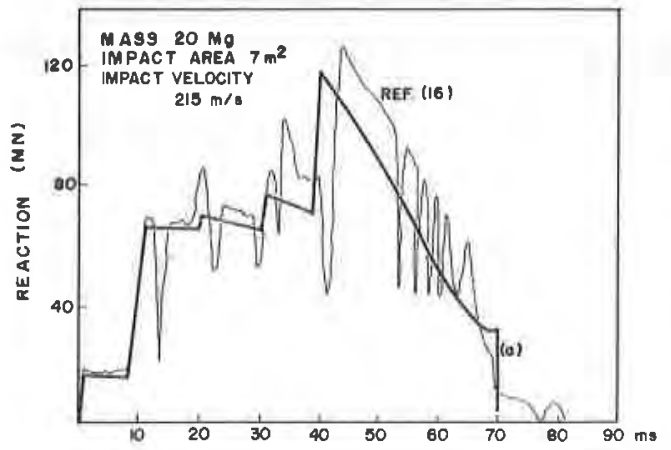

Fig. 4.4. Vertical reaction for a Phantom F4 impinging against a rigid target.

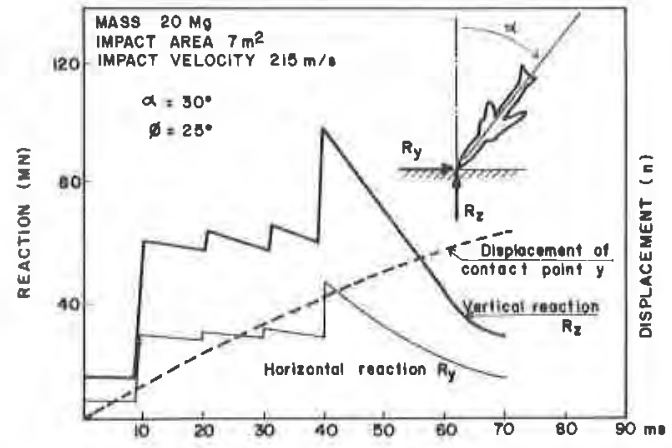

Fig. 4.5. Vertical and horizontal reactions and displacement of contact point for a Phantom $F 4$ impinging against rigid target $\left(\alpha=30^{\circ}\right)$. 